\title{
Transgene-mediated cosuppression in the $C$. elegans germ line
}

\begin{abstract}
Abby F. Dernburg, ${ }^{1}$ Jonathan Zalevsky, ${ }^{1}$ Mónica P. Colaiácovo, and Anne M. Villeneuve ${ }^{2}$

Departments of Developmental Biology and Genetics, Stanford University School of Medicine, Stanford, California 94305-5329 USA
\end{abstract}

Functional silencing of chromosomal loci can be induced by transgenes (cosuppression) or by introduction of double-stranded RNA (RNAi). Here, we demonstrate the generality of and define rules for a transgene-mediated cosuppression phenomenon in the Caenorhabditis elegans germ line. Functional repression is not a consequence of persistent physical association between transgenes and endogenous genes or of mutations in affected genes. The cosuppression mechanism likely involves an RNA mediator that defines its target specificity, reminiscent of RNAi. Cosuppression is strongly abrogated in rde-2 and mut-7 mutants, but is not blocked in an rde-1 mutant, indicating that cosuppression and RNAi have overlapping but distinct genetic requirements.

Received February 17, 2000; revised version accepted May 4, 2000.

Functional silencing of specific genes can be deliberately induced in a wide variety of organisms, either by introduction of homologous transgenes (cosuppression or quelling) (Cogoni and Macino 1997; Ruiz et al. 1998; Vaucheret et al. 1998; Jensen et al. 1999) or by delivery of double-stranded RNA molecules homologous to the target locus [RNA interference (RNAi); Guo and Kemphues 1995; Fire et al. 1998; Kennerdell and Carthew 1998; Ngo et al. 1998; Wianny and Zernicka-Goetz 2000]. These observations are exciting because they point to the existence of unexpected biological processes. However, it remains uncertain how many distinct mechanisms may be involved.

Post-transcriptional mechanisms appear to play roles in diverse examples of silencing. For some instances of cosuppression in plants and quelling in Neurospora, inhibition of gene function is achieved by elimination of specific transcripts (Cogoni et al. 1996; Vaucheret et al. 1998). Studies in Caenorhabditis elegans and trypanosomes indicate that RNAi also involves post-transcriptional removal of targeted transcripts (Montgomery et al. 1998; Ngo et al. 1998). When primed with doublestranded RNA, Drosophila extracts that mimic many

[Key Words: Cosuppression; RNA; silencing; C. elegans; rde-1; rde-2; mut-7]

${ }^{1}$ These authors contributed equally to this work.

${ }^{2}$ Corresponding author.

E-MAIL villen@cmgm.stanford.edu; FAX (650) 725-7739. properties of RNAi will degrade specific RNA substrates, clearly a post-transcriptional event (Tuschl et al. 1999; Hammond et al. 2000; Zamore et al. 2000).

Evidence for additional similarities between RNAi and other post-transcriptional gene silencing (PTGS) phenomena is mounting. Both quelling in Neurospora and RNAi in the C. elegans germ line require homologs of an RNA-dependent RNA polymerase (Schiebel et al. 1998; Cogoni and Macino 1999; Smardon et al. 2000). Low molecular weight RNAs corresponding to the affected gene are induced in several instances of PTGS in plants (Hamilton and Baulcombe 1999); RNA species of similar size have now been identified in Drosophila extracts that have sequence-specific RNA-degradation activity in vitro (Hammond et al. 2000; Zamore et al. 2000).

In C. elegans, RNAi can be used to inactivate genes in either the soma or the germ line. However, cosuppression effects are evidently rare for genes required in the $C$. elegans soma. The standard method for generating transgenic nematodes results in a heritable extrachromosomal array containing several hundred copies of each injected DNA (Stinchcomb et al. 1985). For many genes with somatic functions, expression from an array recapitulates the normal expression pattern of the gene with sufficient fidelity to complement loss-of-function mutations and to serve as an expression reporter (Mello and Fire 1995). Thousands of transgenic nematode lines have been generated over the years, but only one case of a somatic cosuppression-like effect has been reported, affecting the unc-22 gene (Fire et al. 1991).

In contrast, there have been hints that cosuppression may occur more readily in the nematode germ line. Expression from transgene arrays in the germ line has proven notoriously difficult (Mello and Fire 1995). A few investigators have also noted that the presence of a highcopy transgene array in otherwise wild-type worms in some cases mimicked the germ-line phenotype produced by a loss-of-function mutation in the corresponding gene (Jones and Schedl 1995; Gaudet et al. 1996). For the fem-1 gene, phenocopy required a transgene with an intact promoter (Gaudet et al. 1996). However, both the generality and the implications of these observations were unclear.

Here, we demonstrate that induction of loss-of-function phenocopy by high-copy transgene arrays is not an anomaly, but rather is the reproducible outcome for many germ-line-active genes. Further, we define the basis for target gene specificity and the character of the sequence and genetic requirements for cosuppression, revealing both similarities to and distinctions from RNAi.

\section{Results and Discussion}

\section{Transgene arrays induce loss-of-function phenocopy}

We first observed induction of phenocopy by transgene arrays during our analysis of him-14, a gene required for meiotic crossing over (Zalevsky et al. 1999). A reporter construct designed to express an HIM-14::GFP fusion was coinjected with the rol-6(su1006) marker (Mello et 
al. 1991) into wild-type worms, and transgenic lines were produced (Fig. 1, DNA 1). All seven $\mathrm{F}_{1}$ worms that transmitted the marker transgene to their progeny also exhibited a constellation of phenotypes diagnostic of a defect in meiotic recombination (Dernburg et al. 1998; Zalevsky et al. 1999). They produced many embryos, most of which died; among the few survivors, many were males. Oocyte nuclei in transgenic animals from these lines exhibited a high frequency of achiasmate chromosomes. This him-14 loss-of-function (Him) phenocopy was reproduced with a PCR product corresponding to the entire unmodified him-14 gene (Fig. 1, DNA 2), and thus is not specific to the GFP construct. Furthermore, phenocopy is not caused by HIM-14 overexpression, as phenocopy was readily induced with PCR products containing either a him-14 null allele (Zalevsky et al. 1999) or severely truncated versions of the gene (Fig. 1, DNAs 3, 4, 5, and 7). Similarly, transgenes with incomplete coding regions had induced phenocopy of unc-22 in the soma (Fire et al. 1991).

A recombination-defective phenotype could also be in-

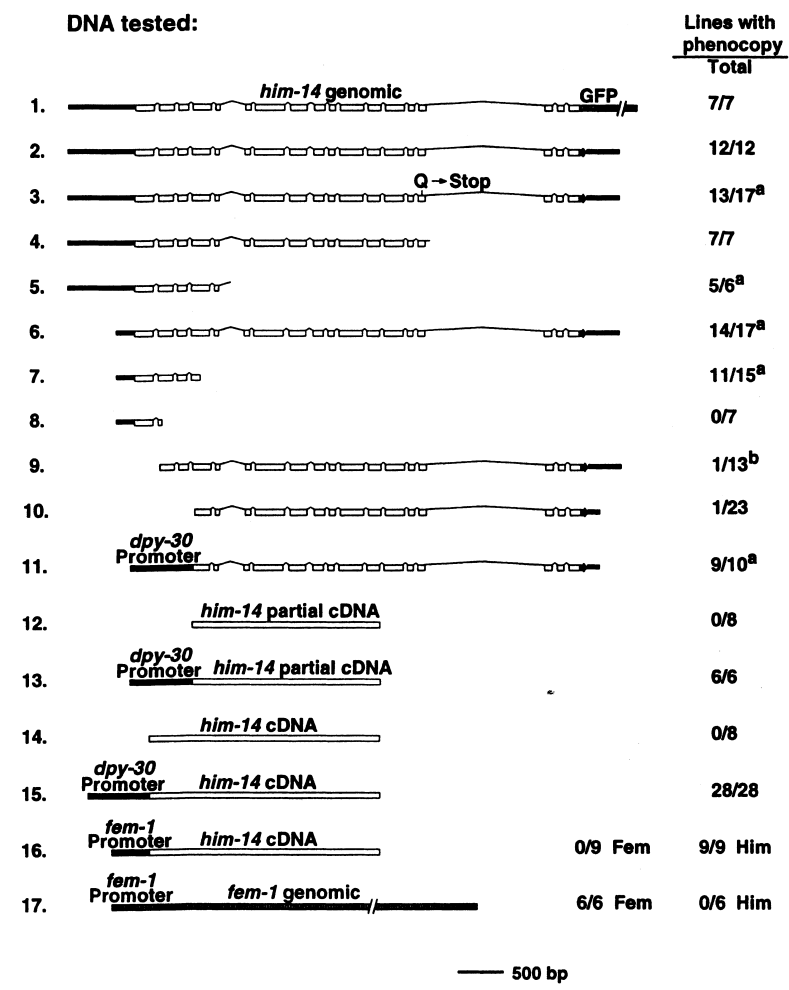

Figure 1. Induction of him-14 phenocopy by transgene arrays. DNAs tested for their ability to elicit a Him (1-17) or Fem (16-17) phenocopy are shown (see Materials and Methods for details). For each DNA, we indicate the number of transgenic lines that exhibited phenocopy/total number of lines obtained. Except where noted ${ }^{\mathrm{a}}$, phenocopy was assessed both in the germ lines of the founding transgenic $F_{1}$ hermaphrodites and in the germ lines of their progeny. For DNAs that efficiently induced Him phenocopy, most lines $(72 \%-100 \%)$ exhibited phenocopy immediately in the germ lines of the $\mathrm{F}_{1}$; where tested, the remainder showed Him phenocopy in the $\mathrm{F}_{2}$ generation. ${ }^{a}$ Phenocopy was not assessed subsequent to the $F_{1}$ generation for these lines. ${ }^{\mathrm{b}}$ A partial Him phenocopy was observed in this line. duced by arrays containing DNA corresponding to spo11 or msh-5, two other genes required for meiotic recombination (Dernburg et al. 1998; Kelly et al. 2000). Figure 2 shows oocyte nuclei from an affected hermaphrodite carrying a spo-11(+) transgene array. Wild-type oocytes contain six bivalents, pairs of homologous chromosomes attached by chiasmata as a consequence of crossover events that occurred at an earlier stage. In contrast, oocytes from animals exhibiting spo-11 (or him-14 or msh5) phenocopy have up to 12 univalent chromosomes that lack chiasmata, indicative of a failure in crossing over.

\section{Evidence for involvement of an RNA mediator}

Transgene-induced phenocopy is not due to the induction of mutations in the DNA sequence of the chromosomal loci, as loss of the transgene array invariably leads to restoration of the wild-type phenotype. Animals that carry arrays transmit them to some of their progeny, but they also produce progeny lacking the array because of loss during germ-line mitosis or meiosis. For some DNAs, only progeny that inherited the array exhibited phenocopy. For other DNAs, phenocopy sometimes persisted for one or more generations after loss of the array; however, in all cases, the wild-type phenotype was ultimately restored in subsequent generations. Quantitative analysis of this phenomenon (Table 1) hints that persistence of phenocopy after array loss may correlate with overall potency of a transgene in eliciting phenocopy: In the cases where persistence was not observed, not all array-bearing animals exhibited phenocopy. In the case where persistence was observed, all array-bearing animals exhibited phenocopy.

Restoration of the wild-type phenotype differentiates this transgene-induced phenocopy from phenomena such as RIP (repeat-induced point mutation) in Neurospora, wherein induction of meiosis in strains carrying a

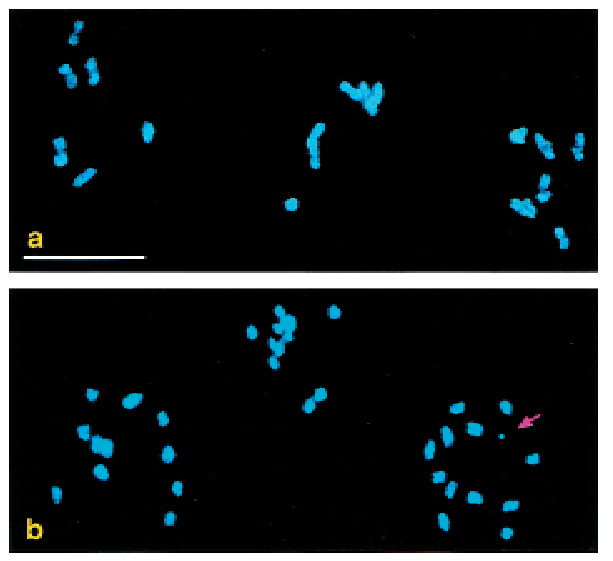

Figure 2. spo-11 phenocopy induced by a transgene array. (a) Three wild-type oocyte nuclei at the end of meiotic prophase. Each contains six bivalents, representing the six pairs of homologous chromosomes linked by chiasmata. (b) Same stage from an animal carrying a transgene array with many copies of the spo-11(+) gene. Loss of function of this gene has resulted in the absence of chiasmata. In some nuclei, one or more extrachromosomal arrays (arrow) are observed in addition to the 12 univalent chromosomes. Bar, $10 \mu \mathrm{m}$. 
Table 1. Phenocopy and inheritance of transgene arrays

\begin{tabular}{|c|c|c|c|}
\hline \multirow[b]{2}{*}{$\begin{array}{l}\text { Structure of transgene } \\
\text { present in the array }\end{array}$} & \multicolumn{3}{|c|}{$\begin{array}{l}\text { No. of individuals with } \\
\text { Him phenocopy/total } \\
\text { individuals scored }\end{array}$} \\
\hline & Rol & $\begin{array}{l}\text { Non- } \\
\text { Rol }\end{array}$ & $\begin{array}{l}\text { Progeny from } \\
\text { non-Rol Him }\end{array}$ \\
\hline 1. him-14 genomic: C-terminal GFP & $51 / 69$ & $0 / 39$ & N.A. \\
\hline 15. $d p y-30$ promoter: him14 cDNA & $29 / 29$ & $11 / 14$ & $17 / 19$ \\
\hline 16. fem-1 promoter: $\operatorname{him} 14 \mathrm{cDNA}$ & $16 / 21$ & $0 / 8$ & N.A. \\
\hline
\end{tabular}

The Rol phenotype identified animals carrying the transgene array. Rol and non-Rol progeny from array-bearing parents were plated individually and assessed for Him phenocopy. When non-Rol Him animals were observed, their hermaphrodite progeny were plated to assess persistence of phenocopy. Progeny of animals that were Him at this second generation following array loss were allowed to self-fertilize for 1-2 additional generations, and non-Him animals invariably overtook the population. N.A. Not applicable.

${ }^{a}$ Numbers correspond to Fig. 1. For each DNA, worms from 2-4 independent transgenic lines were tested.

transgene leads to targeted mutagenesis of both the endogene and the transgene (Selker 1990). Furthermore, examples of persistence of phenocopy after array loss suggest the possible involvement of a non-DNA mediator.

How might high-copy transgene arrays repress the function of chromosomal copies of the gene? Previous studies suggest that high-copy transgene arrays may adopt a transcriptionally silent heterochromatin-like state in the nematode germ line (Kelly et al. 1997; Kelly and Fire 1998). In Drosophila, physical association between a block of repetitive, heterochromatic DNA and a euchromatic gene can silence expression of the gene, a phenomenon known as trans-inactivation (Dernburg et al. 1996). Using FISH, we tested whether cosuppression might be a consequence of physical pairing of the spo-11 extrachromosomal array with the chromosomal spo-11 loci (Fig. 3). These experiments failed to detect any pairing between the transgene array and the spo-11 chromo- somal loci, either in premeiotic nuclei or at any stage of meiotic prophase in affected adult hermaphrodites. In contrast, pairing was consistently detected between the two chromosomal spo-11 loci during meiotic prophase, demonstrating the sensitivity of the cytological assay. Significantly, a substantial fraction of meiotic nuclei did not contain arrays, despite the fact that all oocyte nuclei in the germ line of affected animals display a mutant phenotype (Figs. 2 and 3). These data indicate that physical pairing of the spo-11 extrachromosomal array with the endogenous spo-11 loci at the time of expression cannot be responsible for their functional repression. Furthermore, they suggest that cosuppression may involve a diffusible mediator.

We considered the possibility that a transient physical association with the array might have occurred earlier in development and could have imprinted a silent state at the chromosomal locus. However, when we examined germ-line precursor cells at other stages, we saw no evidence of such an association (Fig. 3). Together with our other results (below), these observations favor the idea that germ-line cosuppression is distinct from trans-inactivation and does not result from direct contact between the array and the affected chromosomal loci.

Several lines of evidence suggest that the ability to generate transcripts from the array is required either to establish or maintain functional repression of the endogenous genes. First, efficient induction of phenocopy appears to require both a promoter region and sufficient transcribed sequences. Although phenocopy was efficiently induced by a PCR product containing the entire him-14 coding sequence plus $186 \mathrm{bp}$ upstream of the trans-splice acceptor and initiation codon (Fig. 1, DNA 6), PCR products containing the vast majority of the coding sequence but no $5^{\prime}$ upstream region only very rarely (2/34 lines) produced phenocopy (Fig. 1, DNAs 9 and 10). Furthermore, a PCR product consisting of the 186-bp upstream region, the first exon, and the first intron also
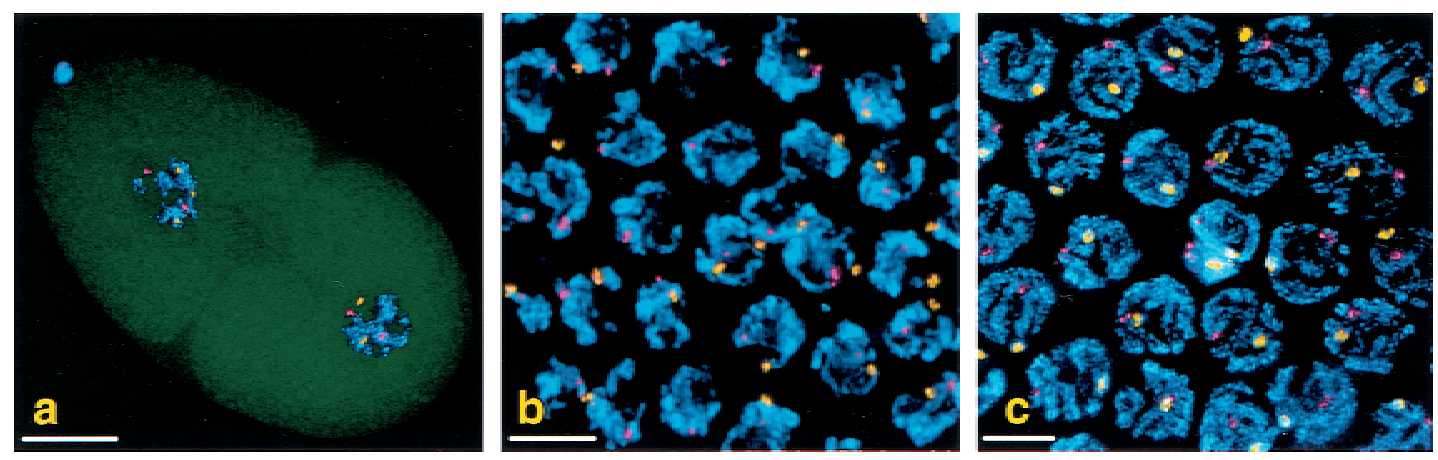

Figure 3. Absence of pairing between a transgene array and the affected chromosomal locus. The subnuclear location of extrachromosomal arrays and the affected chromosomal loci were examined using FISH. (Yellow) Hybridization to the array; (magenta) chromosome region containing the spo-11 locus. (a) A two-cell embryo; a projection through the nuclei is superimposed on an image of green autofluorescence to show the embryo's outline. The condensed nucleus at the anterior pole is the polar body. The posterior P1 cell (lower right) gives rise to the adult germ line. In each of the two interphase nuclei, both chromosomal loci are detected, as well as either two or three arrays. $(b, c)$ Nuclei in early meiotic prophase and mid-prophase (pachytene), respectively. In each nucleus, the two homologous chromosomal loci are paired with each other (resulting in a single focus of hybridization) but are not associated with the extrachromosomal arrays. Due to mitotic instability, some nuclei do not contain arrays $(b)$, yet the loss of gene function affects all nuclei. Bar in $a, 10 \mu \mathrm{m}$; in $b$ and $c, 5 \mu \mathrm{m}$. 
failed to induce phenocopy, indicating that upstream sequences alone are not sufficient (Fig. 1, DNA 8).

Fusion of the ubiquitously expressed $d p y-30$ promoter (Hsu et al. 1995) to one of the ineffective 5'-truncated versions of the him-14 gene restored efficient induction of phenocopy (Fig. 1, DNA 11), strengthening the conclusion that the $5^{\prime}$-truncated gene was ineffective because it lacked a promoter. Moreover, whereas neither a partial cDNA nor a cDNA corresponding to the entire him-14 coding region was capable of producing phenocopy, either cDNA fused to the heterologous $d p y-30$ promoter elicited phenocopy very efficiently (Fig. 1, DNAs 12-15). Thus only him-14 coding sequences are necessary to specify him-14 phenocopy.

Experiments using a chimeric DNA in which the promoter region of the fem-1 gene was fused to the him-14 cDNA demonstrated further that the specificity of transgene-induced phenocopy resides in the transcript, not in the promoter region. The fem-1 gene is required for male somatic sexual differentiation and for spermatogenesis in the germ lines of both males and hermaphrodites (Doniach and Hodgkin 1984). Loss of fem-1 function in the germ line results in the production of only oocytes and no sperm, transforming self-fertilizing hermaphrodites into fertile but obligate-crossing females. Gaudet et al. (1996) reported that high-copy fem-1 transgenes that were capable of rescuing male somatic sexual development in a fem-1 mutant paradoxically feminized the germ lines of wild-type animals. As we have observed for the him-14 phenocopy reported here, this fem-1 germline phenocopy also required both the $5^{\prime}$ upstream promoter region and fem-1 transcribed sequences.

fem-1 and him-14 are required for distinct and independent aspects of germ line function, making it possible to score both loss-of-function phenotypes simultaneously. This allowed us to demonstrate unambiguously that the transcript sequence rather than that of the promoter region dictates the type of phenocopy observed (Fig. 1, DNAs 16 and 17). We found that the fem-1 promoter region fused to a him-14 full-length cDNA elicited robust him-14 phenocopy in 9/9 transgenic lines, but did not cause a fem-1 phenocopy. In contrast, control fem-1 transgene arrays efficiently induced fem-1 phenocopy but did not cause a Him phenotype.

The most economical explanation for all of these results is that transcription from the array is required either to establish or maintain functional repression of the endogenous genes. We favor this interpretation over alternative formal possibilities, such as promoters inducing alterations in surrounding chromatin to facilitate transient physical interaction between transgenes and chromosomal loci. Furthermore, we can rule out one alternative hypothesis, that phenocopy results from regulatory elements titrating specific transcription factors.

Both the apparent requirement for transgene transcription and the dependence of phenotypic specificity on transcript rather than promoter sequences are features shared with cosuppression phenomena previously described in plants (Vaucheret et al. 1998). Involvement of a diffusible mediator is also a property of both cosuppresion in plants and quelling in Neurospora (Cogoni et al. 1996; Palauqui et al. 1997). Moreover, the likely involvement of RNA molecules suggests that transgene-mediated cosuppression may be mechanistically related to RNAi.

\section{Overlapping but distinct genetic requirements for transgene-mediated cosuppression and RNAi}

Genetic analysis has identified at least nine C. elegans genes required for efficient RNAi in the soma and/or germ line (Ketting et al. 1999; Tabara et al. 1999; Smardon et al. 2000). Most fall into two classes: Those required only for dsRNAi, such as rde-1, and those also required to suppress germ-line transposon mobilization, including $r d e-2$ and mut-7.

Whereas mutations in $r d e-1$ profoundly suppress RNAi (Tabara et al. 1999), we found that an rde-1 mutation does not prevent cosuppression. We observed strong spo-11 phenocopy in 9/9 transgenic lines generated by introducing wild-type spo-11 genes into rde-1 mutant hermaphrodites. Thus, if cosuppression and RNAi do elicit gene silencing by a common mechanism, rde-1 must function in an upstream event in RNAi that is not required for cosuppression. Grishok et al. (2000) independently concluded that $r d e-1$ functions at an upstream step in RNAi. They showed that $r d e-1$ is required for initial formation of a heritable interfering agent, but is not needed for interference thereafter.

Although $r d e-1$ is not required for cosuppression, $r d e-2$ and mut-7 are essential (Table 2). Our findings that mut-7 is required for cosuppression but $r d e-1$ is not are in agreement with results from an independent study (Ketting and Plasterk 2000). When arrays were generated in rde-2 or mut-7 mutants, we did not observe cosuppression in the founding transgenic animal or in subsequent generations of the resulting transgenic lines. Nevertheless, arrays generated in these mutants are capable of eliciting cosuppression. This capability was demonstrated by crossing array-bearing rde-2 or mut-7 hermaphrodites with wild-type males to generate $+/ r d e-2$ or $+/$ mut $-7 \mathrm{~F}_{1}$ hermaphrodites carrying the array. When arrays contained spo-11 transgenes, $+/$ rde -2 or $+/$ mut -7 array-bearing $\mathrm{F}_{1} \mathrm{~s}$ consistently exhibited a robust recombination-defective phenotype ( $\mathrm{Rec}^{-}$; Table 2). When arrays contained a truncated him-14 transgene, only a fraction of $+/$ rde- 2 or $+/$ mut -7 array-bearing $\mathrm{F}_{1} \mathrm{~s}$ exhibited a robust $\mathrm{Rec}^{-}$phenotype; nevertheless, all produced $\mathrm{Rec}^{-} \mathrm{F}_{2}$ progeny at high frequency (Table 2).

Grishok et al. (2000) showed that rde-2 and mut-7 function downstream of rde-1 in the RNAi pathway. rde-2 and mut-7 are dispensable for initial formation of a heritable interfering agent, but are required at a later step to achieve interference. Because rde-2 and mut-7 (but not rde-1) are also required for transposon silencing (Ketting et al. 1999; Tabara et al. 1999), they proposed a model in which transposons would use an alternative pathway independent of $r d e-1$ to generate a secondary interfering agent, and then achieve silencing through a common effector pathway that includes rde-2 and mut-7. Our finding that cosuppression also requires $r d e-2$ and mut- 7 but not rde-1 accords with this framework of a common 
Table 2. rde-2 and mut-7 mutants are deficient for cosuppression

\begin{tabular}{|c|c|c|}
\hline \multirow[b]{2}{*}{ Genotype } & \multicolumn{2}{|c|}{$\operatorname{Rec}^{-}$phenocopy/total } \\
\hline & $\begin{array}{l}\text { Plate assay } \\
\text { (produced } \\
\geq 94 \% \\
\text { dead eggs) }\end{array}$ & $\begin{array}{c}\text { DAPI assay } \\
\text { (achiasmate } \\
\text { chromosomes } \\
\text { in oocyte } \\
\text { nuclei) }\end{array}$ \\
\hline rde-2; meEx301[spo-11] & $0 / 8$ & $0 / 13$ \\
\hline$+/ r d e-2 ;$ meEx301[spo-11] & $7 / 7$ & $11 / 11$ \\
\hline mut-7; meEx300[spo-11] & $0 / 15$ & $0 / 18$ \\
\hline +/mut-7; meEx300[spo-11] & $15 / 15$ & $9 / 9$ \\
\hline rde-2; meEx305[him-14] & $0 / 8$ & $0 / 6$ \\
\hline +/rde-2; meEx305[him-14] & $\left.5 / 12(\text { in })_{1}\right)^{a}$ & $\begin{array}{c}\text { 4/10 } \operatorname{Rec}^{-}\left(\text {in } F_{1}\right) \\
\text { 4/10 partial } \operatorname{Rec}^{-}\left(\text {in } F_{1}\right)\end{array}$ \\
\hline rde-2; meEx306\{him-14] & $0 / 10$ & $0 / 16$ \\
\hline +/rde-2; meEx306\{him-14] & $2 / 5\left(\text { in }_{F_{1}}\right)^{b}$ & $2 / 5\left(\right.$ in $\left.F_{1}\right)$ \\
\hline mut-7; meEx307[him-14] & $0 / 10$ & $0 / 16$ \\
\hline +/mut-7; meEx307[him-14] & $1 / 6\left(\text { in } F_{1}\right)^{\mathrm{c}}$ & $1 / 6\left(\right.$ in $\left.F_{1}\right)$ \\
\hline
\end{tabular}

Transgene arrays contained either the spo-11 gene (meEx301, meEx300) or a truncated him-14 gene (DNA \#4 from Fig. 1; meEx305, 306, 307).

${ }^{a} 7 / 7 \mathrm{Rec}^{+} \mathrm{F}_{1}$ s gave $\operatorname{Rec}^{-} \mathrm{F}_{2}$ progeny by DAPI assay $\left(87 \mathrm{Rec}^{-} / 110\right.$ total $\mathrm{F}_{2} \mathrm{~s}$ scored $=79 \%$ ).

${ }^{\mathrm{b}} 3 / 3 \mathrm{Rec}^{+} \mathrm{F}_{1} \mathrm{~s}$ gave $\operatorname{Rec}^{-} \mathrm{F}_{2}$ progeny by DAPI assay $\left(23 \mathrm{Rec}^{-} / 34\right.$ total $\mathrm{F}_{2} \mathrm{~s}$ scored $=68 \%$ ).

${ }^{c} 5 / 5 \operatorname{Rec}^{+} \mathrm{F}_{2} \mathrm{~s}$ gave $\operatorname{Rec}^{-} \mathrm{F}_{2}$ progeny by DAPI assay $\left(61 \operatorname{Rec}^{-} / 94\right.$ total $\mathrm{F}_{2} \mathrm{~S}$ scored $=65 \%$ ).

downstream interference mechanism acting in response to a variety of initiating stimuli. However, this model leaves open the questions of the nature of the primary trigger(s) for cosuppression and transposon silencing and how these primary triggers might be converted into a secondary interfering agent. The apparent requirement for transgene transcription to elicit cosuppression suggests that RNA molecules may constitute the primary trigger, but if so, the pertinent transcripts must be aberrant in some way to be recognized as triggers for silencing.

Transgene arrays, normally silent in the germ line, show elevated expression in the germ lines of mut-7 mutants (Tabara et al. 1999). This phenotype could be explained in part as a consequence of reduced cosuppression, which probably contributes to functional repression of transgenes in addition to silencing endogenous genes. However, we have also observed that arrays appear to be less condensed in mut-7 and rde-2 germ lines than in wild-type germ lines. Further, it is more difficult to generate arrays in rde-2 and mut-7 strains (although once generated, arrays are transmitted efficiently). These and other pleiotropic effects such as chromosome missegregation (Ketting et al. 1999; Tabara et al. 1999) are difficult to reconcile with a model in which RDE-2 and MUT-7 act solely as downstream effectors of a targeted RNA degradation process.

One possibility is that the chromatin structure of repetitive transgene arrays in the germ line normally promotes the formation of aberrant transcripts that elicit interference. In mut-7 and rde-2 mutants, germ line chromatin may be altered in such a way as to prevent the formation of these aberrant transcripts while also contributing to the abnormal behavior of chromosomes. In this scenario, RDE-2 and MUT-7 would function in an early step in the cosuppression process, in the production of the initial triggering molecules. This scenario does not preclude the possibility that RDE-2 and MUT-7 might also function as downstream effectors of cosuppression, as they clearly do for RNAi (Grishok et al. 2000). A role for $r d e-2$ and mut-7 in regulating chromatin structure could help to explain our observation that him-14 transgene arrays were more likely to elicit strong cosuppression in $\mathrm{F}_{2}$ animals than in $\mathrm{F}_{1}$ animals generated following a cross between rde-2 or mut-7 hermaphrodites and wild-type males (Table 2). The history of the arrays in the rde-2 or mut-7 background may have affected the probability of generating sufficient triggering molecules.

\section{A tool for investigating germ-line gene function}

Transgene-mediated cosuppression provides a valuable method for inhibiting gene function in the nematode germ line. We have now targeted numerous additional genes, eliciting diverse germ-line phenotypes including failure in spindle assembly (e.g., C41G7.2) and altered meiotic progression (e.g., R06C7.8).

In certain cases, cosuppression provides experimental advantages over RNAi. For some phenotypes, stable cosuppressed transgenic lines can be generated, permitting assessment of phenotype over many generations. Because the effects of cosuppression appear to be largely restricted to the germ line, the cosuppression approach can also reveal germ line-specific functions for essential genes for which mutation or RNAi would result in lethality.

\section{Materials and methods}

Generation of transgenic animals

For Fig. 1, DNAs (50 ng/ $\mu \mathrm{l})$ were coinjected with $50 \mathrm{ng} / \mu \mathrm{l}$ plasmid pRF4 (Mello et al. 1991) into wild-type (N2) hermaphrodites. DNA 1 contains the him-14 coding sequence and upstream region cloned in GFP fusion vector pPD95.77. DNAs 2 and 4-10 were amplified from N2 genomic DNA. All PCR products gave single bands of expected size by gel analysis; those that failed to elicit phenocopy were further verified by restriction digestion. DNA 2 includes the entire him-14 coding sequence plus $736 \mathrm{bp}$ upstream of the trans-splice acceptor site that immediately precedes the initiation codon and $452 \mathrm{bp}$ downstream of the stop codon (including the $3^{\prime}$ UTR, indicated in black); 4-10 include the indicated subsets of this sequence. DNA 3 is a PCR product amplified from him14(it21) genomic DNA. DNAs 11, 13, and 15 contain 5'-truncated him14 genomic DNA, a partial him-14 cDNA starting at codon 155 , or a cDNA corresponding to the entire him-14 coding sequence cloned downstream of the 683-bp $d p y-30$ promoter region (Hsu et al. 1995) in expression vector pdh $38 \Delta \mathrm{M}$, a derivative of pBluescript KS(-). DNAs 12 and 14 contain these two cDNAs cloned in pBluescript SK(-). DNA 17 is a $13-\mathrm{kb}$ PCR product containing the entire fem-1 gene. DNA 16 is a chimeric PCR product amplified from the ligation products of the insert from 14 and a genomic PCR product corresponding to the 404-bp fem-1 promoter region (Gaudet et al. 1996). A 3-kb genomic PCR product spanning the spo-11 locus was used for all the spo-11 experiments. The coinjection marker was either plasmid pMM016B containing unc-119(+) (Maduro and Pilgrim 1995), injected into unc-119(e2498) worms (Figs. 2-3), or pRF4, injected into N2 or rde-1(ne219). All DNAs were injectied at 50-100 ng/ul. For experiments in Table 2, spo-11 DNA or DNA 4 from Fig. 1 were coinjected with pRF4, each at $50 \mathrm{ng} / \mu \mathrm{l}$, into the gonads of $r d e$ 2(ne221) or mut-7(pk204) hermaphrodites. In all cases, $\mathrm{F}_{1}$ worms expressing the transformation marker were plated individually, and their broods were scored for transmission of the transgene array to their progeny and for induction of phenocopy.

Cytology

Fixation, DAPI staining, and FISH were carried out as in Dernburg and Sedat (1998) and Dernburg et al. (1998). Arrays were detected with a probe 
composed of the spo-11 and unc-119 DNAs used to generate the transgenic animals. A probe specific to the chromosomal spo-11 locus was generated from four cosmids flanking but not including the spo-11 gene. Probes were digested and 3'-end labeled with FITC-N4-dCTP and Cy3dUTP, respectively, as in Dernburg and Sedat (1998). Images were acquired with a DeltaVision microscope then deconvolved and displayed with the accompanying software.

\section{Acknowledgments}

We thank the Caenorhabditis Genetics Center, the Sanger Centre, C. Mello, and A. Fire for strains and clones, and K. Kelly for technical help. This work was funded by fellowships from the Damon Runyon-Walter Winchell Foundation and the Leukemia and Lymphoma Society to A.F.D., and the Bank of America-Giannini Foundation to M.P.C. and by grants from the NIH and the Chicago Community Trust to A.M.V.

The publication costs of this article were defrayed in part by payment of page charges. This article must therefore be hereby marked "advertisement" in accordance with 18 USC section 1734 solely to indicate this fact.

\section{References}

Cogoni, C. and Macino, G. 1997. Conservation of transgene-induced post-transcriptional gene silencing in plants and fungi. Trends Plant Sci. 2: 438-443.

-1999. Gene silencing in Neurospora crassa requires a protein homologous to RNA-dependent RNA polymerase. Nature 399: 166169.

Cogoni, C., Irelan, J.T., Schumacher, M., Schmidhauser, T.J., Selker, E.U., and Macino, G. 1996. Transgene silencing of the al-1 gene in vegetative cells of Neurospora is mediated by a cytoplasmic effector and does not depend on DNA-DNA interactions or DNA methylation. EMBO J. 15: 3153-3163.

Dernburg, A.F. and Sedat, J.W. 1998. Mapping three-dimensional chromosome architecture in situ. In Nuclear Structure and Function (ed. M. Berrios), pp. 187-233. Academic Press, San Diego.

Dernburg, A.F., Broman, K.W. Fung, J.C., Marshall, W.F., Philips, J., Agard, D.A., and Sedat, J.W. 1996. Perturbation of nuclear architecture by long-distance chromosome interactions. Cell 85: 745-759.

Dernburg, A.F., McDonald, K., Moulder, G., Barstead, R., Dresser, M., and Villeneuve, A.M. 1998. Meiotic recombination in C. elegans initiates by a conserved mechanism and is dispensable for homologous chromosome synapsis. Cell 94: 387-398.

Doniach, T. and Hodgkin, J. 1984. A sex-determining gene, fem-1, required for both male and hermaphrodite development in Caenorhabditis elegans. Dev. Biol. 106: 223-235.

Fire, A., Albertson, D., Harrison, S.W., and Moerman, D.G. 1991. Production of antisense RNA leads to effective and specific inhibition of gene expression in C. elegans muscle. Development 113: 503-514.

Fire, A., Xu, S. Montgomery, M.K., Kostas, S.A., Driver, S.E., and Mello, C.C. 1998. Potent and specific genetic interference by doublestranded RNA in Caenorhabditis elegans. Nature 391: 806-811.

Gaudet, J., VanderElst, I., and Spence, A.M. 1996. Post-transcriptional regulation of sex determination in Caenorhabditis elegans: Widespread expression of the sex-determining gene fem-1 in both sexes. Mol. Biol. Cell 7: 1107-1121.

Grishok, A., Tabara, H., and Mello, C.C. 2000. Genetic requirements for inheritance of RNAi in C. elegans. Science 287: 2494-2497.

Guo, S. and Kemphues, K.J. 1995. par-1, a gene required for establishing polarity in C. elegans embryos, encodes a putative Ser/Thr kinase that is asymmetrically distributed. Cell 81: 611-620.

Hamilton, A.J. and Baulcombe, D.C. 1999. A species of small antisense RNA in posttranscriptional gene silencing in plants. Science 286: $950-952$.

Hammond, S.M., Bernstein, E., Beach, D., and Hannon, G.J. 2000. An RNA-directed nuclease mediates post-transcriptional gene silencing in Drosophila cells. Nature 404: 293-296.

Hsu, D.R., Chuang, P.T., and Meyer, B.J. 1995. DPY-30, a nuclear protein essential early in embryogenesis for Caenorhabditis elegans dosage compensation. Development 121: 3323-3334.

Jensen, S., Gassama, M.P., and Heidmann, T. 1999. Taming of transposable elements by homology-dependent gene silencing. Nat. Genet. 21: 209-212.

Jones, A.R. and Schedl, T. 1995. Mutations in gld-1, a female germ cellspecific tumor suppressor gene in Caenorhabditis elegans, affect a conserved domain also found in Src-associated protein Sam68. Genes \& Dev. 9: 1491-1504.

Kelly, W.G. and Fire, A. 1998. Chromatin silencing and the maintenance of a functional germ line in Caenorhabditis elegans. Development 125: 2451-2456

Kelly, K.O., Dernburg, A.F., Stanfield, G.M., and Villeneuve, A.M. 2000. C. elegans msh-5 is required for both normal and radiation-induced meiotic crossing over but not for completion of meiosis. Genetics (in press).

Kelly, W.G., Xu, S., Montgomery, M.K., and Fire, A. 1997. Distinct requirements for somatic and germ line expression of a generally expressed Caernorhabditis elegans gene. Genetics 146: 227-238.

Kennerdell, J.R. and Carthew, R.W. 1998. Use of dsRNA-mediated genetic interference to demonstrate that frizzled and frizzled 2 act in the wingless pathway. Cell 95: 1017-1026.

Ketting, R.F. and Plasterk, R.H. 2000. A genetic link between co-suppression and RNA interference in C. elegans. Nature 404: 296-298.

Ketting, R.F., Haverkamp, T.H., van Luenen, H.G., and Plasterk, R.H 1999. mut-7 of C. elegans, required for transposon silencing and RNA interference, is a homolog of Werner syndrome helicase and RNaseD. Cell 99: 133-141.

Maduro, M. and Pilgrim, D. 1995. Identification and cloning of unc-119, a gene expressed in the Caenorhabditis elegans nervous system. $\mathrm{Ge}$ netics 141: 977-988.

Mello, C. and Fire, A. 1995. DNA transformation. Methods Cell Biol. 48: 451-482.

Mello, C.C., Kramer, J.M., Stinchcomb, D., and Ambros, V. 1991. Efficient gene transfer in C. elegans: Extrachromosomal maintenance and integration of transforming sequences. EMBO J. 10:3959-3970.

Montgomery, M.K., Xu, S., and Fire, A. 1998. RNA as a target of doublestranded RNA-mediated genetic interference in Caenorhabditis elegans. Proc. Nat1. Acad. Sci. 95: 15502-15507.

Ngo, H., Tschudi, C., Gull, K., and Ullu, E. 1998. Double-stranded RNA induces mRNA degradation in Trypanosoma brucei. Proc. Natl. Acad. Sci. 95: 14687-14692.

Palauqui, J.C., Elmayan, T., Pollien, J.M., and Vaucheret, H. 1997. Systemic acquired silencing: Transgene-specific post-transcriptional silencing is transmitted by grafting from silenced stocks to non-silenced scions. EMBO J. 16: 4738-4745.

Ruiz, F., Vayssie, L., Klotz, C., Sperling, L., and Madeddu, L. 1998. Homology-dependent gene silencing in Paramecium. Mol. Biol. Cell 9: 931-943.

Schiebel, W., Pelissier, T., Riedel, L., Thalmeir, S., Schiebel, R., Kempe, D., Lottspeich, F., Sanger, H.L., and Wassenegger, M. 1998. Isolation of an RNA-directed RNA polymerase-specific cDNA clone from tomato. Plant Cell 10: 2087-2101.

Selker, E.U. 1990. Premeiotic instability of repeated sequences in Neurospora crassa. Annu. Rev. Genet. 24: 579-613.

Smardon, A., Spoerke, J.M., Stacey, S.C., Klein, M.E., Mackin, N., and Maine, E.M. 2000. EGO-1 is related to RNA-directed RNA polymerase and functions in germ-line development and RNA interference in C. elegans. Curr. Biol. 10: 169-178.

Stinchcomb, D.T., Shaw, J.E., Carr, S.H., and Hirsh, D. 1985. Extrachromosomal DNA transformation of Caenorhabditis elegans. Mol. Cell. Biol. 5: 3484-3496.

Tabara, H., Sarkissian, M., Kelly, W.G., Fleenor, J., Grishok, A., Timmons, L., Fire, A., and Mello, C.C. 1999. The rde-1 gene, RNA interference, and transposon silencing in C. elegans. Cell 99: 123-132.

Tuschl, T., Zamore, P.D., Lehmann, R., Bartel, D.P., and Sharp, P.A. 1999. Targeted mRNA degradation by double-stranded RNA in vitro. Genes \& Dev. 13: 3191-3197.

Vaucheret, H., Beclin, C., Elmayan, T., Feuerbach, F., Godon, C., Morel, J.B., Mourrain, P., Palauqui, J.C., and Vernhettes, S. 1998. Transgeneinduced gene silencing in plants. Plant J. 16: 651-659.

Wianny, F. and Zernicka-Goetz, M. 2000. Specific interference with gene function by double-stranded RNA in early mouse development. Nat Cell Biol. 2: 70-75.

Zalevsky, J., MacQueen, A.J., Duffy, J.B., Kemphues, K.J. and Villeneuve, A.M. 1999. Crossing over during Caenorhabditis elegans meiosis requires a conserved MutS-based pathway that is partially dispensable in budding yeast. Genetics 153: 1271-1283.

Zamore, P.D., Tuschl, T., Sharp, P.A., and Bartel, D.P. 2000. RNAi: Double-stranded RNA directs the ATP-dependent cleavage of mRNA at 21 to 23 nucleotide intervals. Cell 101: 25-33. 


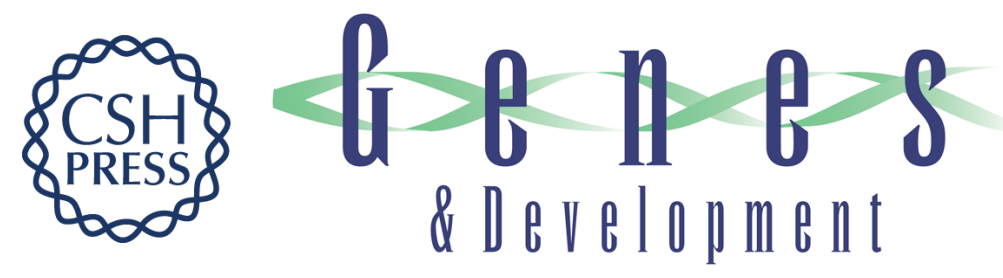

\section{Transgene-mediated cosuppression in the $C$. elegans germ line}

Abby F. Dernburg, Jonathan Zalevsky, Mónica P. Colaiácovo, et al.

Genes Dev. 2000, 14:

Access the most recent version at doi:10.1101/gad.14.13.1578

References This article cites 38 articles, 17 of which can be accessed free at: http://genesdev.cshlp.org/content/14/13/1578.full.html\#ref-list-1

License

Email Alerting Receive free email alerts when new articles cite this article - sign up in the box at the top Service right corner of the article or click here.

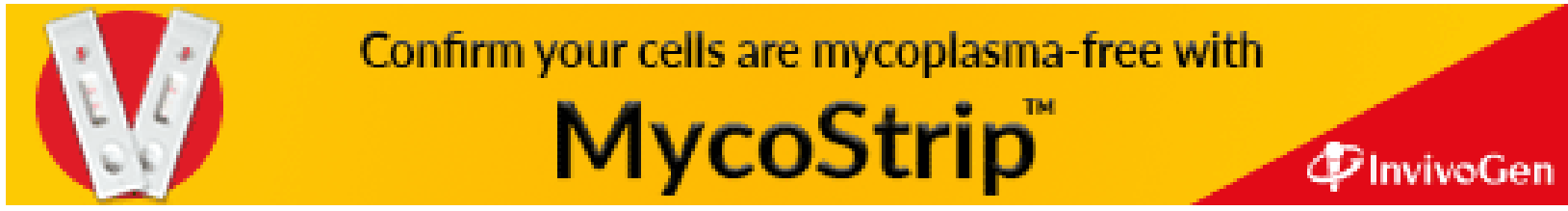

